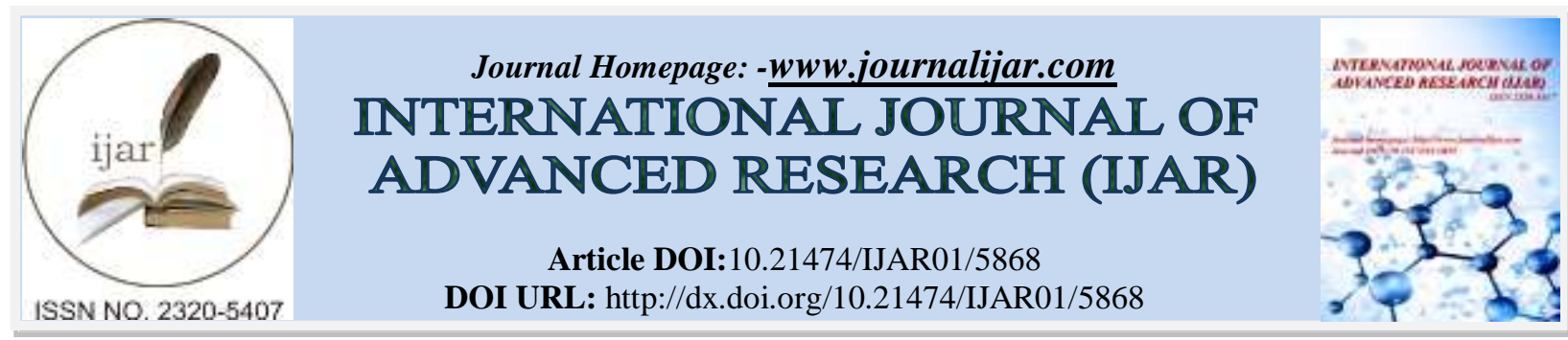

RESEARCH ARTICLE

\title{
PERCEIVED SOCIAL SUPPORT AMONG CLIENTS USING ALCOHOL AND ILLICIT DRUGS AT THE COMPREHENSIVE CARE CENTRE AT THE COAST GENERAL HOSPITAL - KENYA: A DESCRIPTIVE CROSS-SECTIONAL STUDY.
}

\author{
Maina Elizabeth $^{1}$, Wagoro Miriam ${ }^{1}$, Kirui Angeline ${ }^{1}$ and Khasakhala Lincoln ${ }^{2}$. \\ 1. School of Nursing Sciences, College of Health Sciences, University of Nairobi. \\ 2. Department of Psychiatry, College of Health Sciences, University of Nairobi.
}

\section{Manuscript Info}

Manuscript History

Received: 15 September 2017

Final Accepted: 17 October 2017

Published: November 2017

Key words:-

Alcohol and illicit drugs use, perceived social support, coping, People Living with HIV/AIDS.

\begin{abstract}
Poor social support coupled with poor coping mechanisms among people with HIV infection may drive them to alcohol and illicit drug use to cope with the significant psychological challenges that HIV infection presents. In return, this affects adherence to Highly Active Antiretroviral Therapy and progression to Acquired Immune Deficiency Syndrome contributing to high mortality. The aim of the study was to explore perceived social support among clients using alcohol and illicit drugs at the Comprehensive Care Centre of the Coast General Hospital - Mombasa. The CAGE - AID (acronym for cut down, annoyed, guilty, eye opener - adapted to include drug use) tool was used to screen for alcohol and illicit drugs use and clients who scored $\geq 2$ were included in the study. Convenience sampling method was used whereby 235 respondents were consecutively enrolled. Patients with a CAGE-AID score of $\geq 2$ who consented were subjected to a socio-demographic questionnaire and the multidimensional scale of perceived social support (MSPSS). Data analysis was done using Statistical Package for Social Sciences version 21.0. Descriptive statistics were used to examine demographic characteristics. An analysis of variance was done to determine the significance of associations between the population characteristics and the various dimensions of social support. The confidence interval was set at 95\%, p value at $<0.05$.The findings of the study demonstrated inadequate social support among HIV/AIDS infected alcohol and illicit drugs users. Providing social support may decrease the risk of alcohol and illicit drugs use hence better health outcomes. Social support should be strengthened in comprehensive care.
\end{abstract}

Copy Right, IJAR, 2017,. All rights reserved.

Background:-

People infected with the Human Immunodeficiency Virus (HIV) may have various reasons or factors explaining their use of alcohol and illicit drugs. Poor social support is a common problem faced by patients infected with HIV. Poor coping mechanisms among these patients may drive them into use of alcohol and illicit drugs as a means of coping. Factors such as declining health, pain, fear, anxiety and grief which are familiar with HIV diagnosis may increase individual risk of resuming or escalating drug use (Global Initiative on Psychiatry [GIP], 2006). Reactions 
to a positive HIV test, illness progression, or other stressful events may predispose to increased alcohol and illicit drug use (Galvan F.H. et al, 2008)

HIV disease is particularly stigmatizing and is associated with promiscuous sexual behaviour among marginalized groups such as homosexuals, commercial sex workers and injecting drug users (Sayles J. N. et al, 2009). The physical and psychological demands of coping with Human Immunodeficiency Virus/Acquired Immune Deficiency Syndrome can be overwhelming and can influence behaviour such as medication adherence, substance use, sexual risk behaviour, and exercise that, in turn, affect health outcomes (Gore-Felton C. \&Koopman C., 2008).

The frequency of alcohol and illicit drugs use among PLWHA attending clinical care in Kenya is unclear despite the well-known dangers of alcohol and illicit drugs use among PLWHA. Studies carried out in Sub-Saharan Africa reflect a high prevalence. Closer home, a study at a Ugandan university teaching hospital found the prevalence of alcohol use disorders at 12\% (Martinez P. et al, 2008) while one in Ethiopia found the prevalence at 32\% (Soboka M. et al, 2014).

Poor social support coupled with poor coping mechanisms may have a role to play in the prevalence of alcohol and illicit drugs use among people infected with HIV. Researchers have observed that people with higher HIV related stigma which has been associated with low levels of social support engage in harmful alcohol use and substance dependence (Levi-Minzi M and Surratt H, 2014; Holtz, C., et al, 2012). Stressful life events have been associated with nonadherence to HAART and poor treatment access which may be correlated with alcohol and illicit drugs use (Levi-Minzi M and Surratt H, 2014, Leserman, J. et al, 2008).

Social support on the other hand enables HIV infected patients face the psychological and physical demands of coping with medication side effects and co morbidities (Gore-Felton C. \&Koopman C., 2008). In addition, social support is associated with slow AIDS progression and better overall health as found out in other studies (Leserman, J. et al, 2008). The role of social support in the fight against HIV stigmatization therefore cannot be underestimated. How HIV-positive people manage HIV stigma and the strategies that they use can be influenced by the extent of social resources $\{$ family, friends, significant other(s) $\}$ that they have available in their lives (Sayles J. N. et al, 2009, Zhang, Y-X et al, 2014). Individuals with social support may describe/view self more positively enabling them to cope and may also face stressors more confidently knowing that there is someone available to help.

The negative effects of alcohol and illicit drugs use are a worldwide concern. However, psychological variables, as the underlying factors among PLWHA have not been given attention. In Kenya where the present study took place, little if any research has assessed perceived social support among PLWHA who use alcohol and illicit drugs. Such information is important in order to identify those PLWHA at greatest risk of alcohol and illicit drugs use and to inform the development of interventions and services to meet their needs. The present study therefore aimed at assessing perceived social support among this group of clients. A cause-effect relationship could however not be established because the study employed a cross-sectional study design.

\section{Methods:-}

\section{Study setting:-}

The study setting was the Comprehensive Care Centre at the Coast General Hospital, a regional referral hospital in the city of Mombasa- Kenya. It is a public hospital under the County Government of Mombasa-Kenya.

\section{Study design:-}

This was a descriptive cross-sectional study targeting clients infected with HIV/AIDS and using alcohol and illicit drugs with an aim of exploring perceived social support among them. A total of 235 respondents were studied.

\section{Study Population:-}

The study population included all (male and female) HIV infected patients enrolled at the clinic aged 18 years and above, with a CAGE-AID score $\geq 2$ and gave informed consent.

\section{Sampling Procedure:-}

Convenience sampling method was used to obtain the study sample. With the data on the number of patients using alcohol and illicit drugs not available, patients who met the inclusion criteria and gave consent to participate were given the questionnaires to fill until a sample size of 235 was achieved. 


\section{Data Collection and Procedures:-}

We screened for alcohol and drugs use using the CAGE-AID tool (Ewing J., 1984) where we considered a score $\geq 2$ significant. The CAGE-AID tool constitutes four questions necessary to ascertain alcohol and illicit drugs use. The tool was administered to all clients coming to the CCC during their visits as a baseline assessment tool and formed a basis of including clients in the study. Clients of both sexes who had a score of $\geq 2$ (two or more of the four questions) were eligible to participate in the study. After a thorough explanation, eligible respondents signed the consent form. A total of 235 respondents were consecutively enrolled. The respondents then completed a sociodemographic questionnaire and a multidimensional scale of perceived social support (MSPSS) (Zimet G. et al, 1988) which is an easy to administer self report questionnaire. The MSPSS consists of three subscales each having four items- Family (items 3, 4, 8 and 11), Friends (items 6, 7, 9 and 12) and Significant Other (items 1, 2, 5 and 10). The items were presented on a 7-point Likert-type response categories (ranging from very strongly disagree to very strongly agree.) While this scale has not been standardized for this study population, the study made use of it as the scale was found to be a valid and reliable instrument in studies with various target groups of various cultural backgrounds (Olagunju A. et al, 2015, Smith N. et al, 2015).

The scale was then analysed by looking at the scores for each of the three subscales in order to ascertain the perceived social support from each (family, friends and significant other). Each subscale has a possible range of scores from 4 to 28 , with a higher score reflecting a higher level of perceived social support. A low total score indicated a low level of perceived social support.

Data was collected on socio-demographic variables: age, gender, religion, marital status, level of education and occupation; HIV/AIDS status, alcohol and illicit drugs use history and perceived social support.

\section{Recruitment of Participants:-}

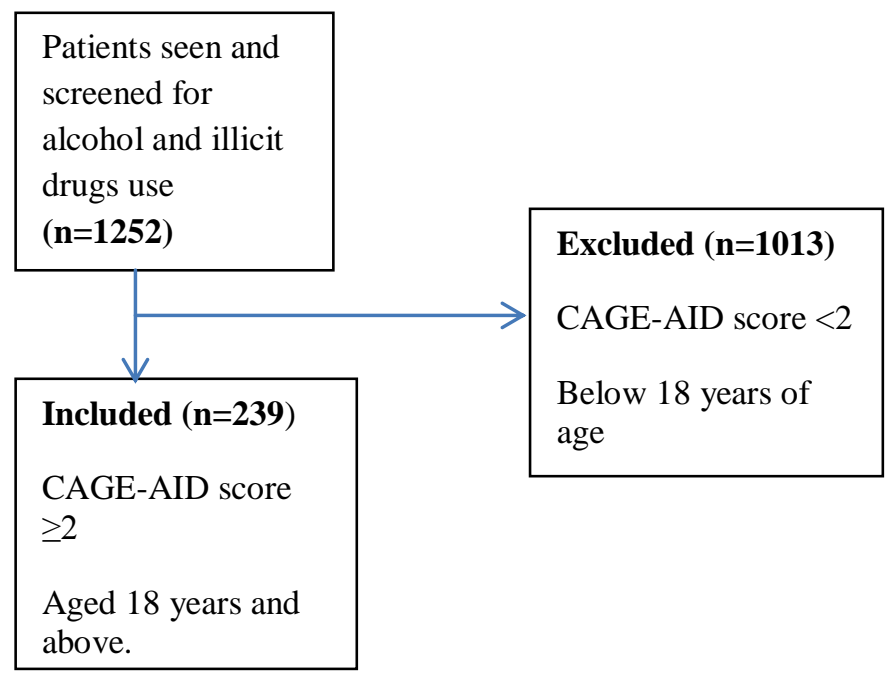

\section{Data Analysis:-}

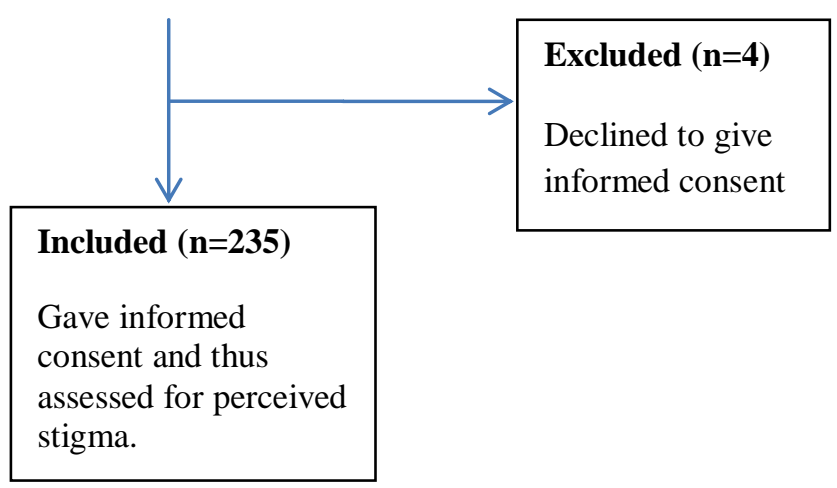




\section{Data Analysis:-}

The sample size was calculated with the help of Cochrane's modification of Fishers et al formula. Data was entered and analysed using the Statistical Package for Social Sciences (SPSS) version 21.0. Descriptive analysis was done using means, ranges, standard deviations and proportions. An analysis of variance (ANOVA) was then done to determine the significance of associations between the population characteristics and the various dimensions of social support.Statistical significance was measured at the 5\% level $(p \leq 0.05)$.

\section{Measures:-}

Screening for alcohol and illicit drugs use was done using the CAGE-AID tool (Ewing J., 1984) where a score $\geq 2$ was considered significant i.e. clients were only eligible if they answered "YES" in two or more of the four questions in the tool.

Perceived social support was measured comparatively among the three sources of social support which constituted three subscales. Each of the subscales has 4 items with a possible range of scores from 4 to 28 . A comparatively higher score among the three sources of social support reflected a higher level of perceived social support.

\section{Ethical Considerations:-}

Ethical review and approval was obtained from Kenyatta National Hospital-University of Nairobi (KNH-UON) Research and Ethics Committee and data collection was authorized by the administration at the Coast General Hospital. Informed consent was sought from individual participants. Data was analyzed and presented anonymously.

\section{Results:-}

The researchers studied 235 patients of which $67.2 \%$ (158) were male. Majority of the respondents, $93.3 \%$ (217) had not joined any HIV/AIDS support group while $90.6 \%$ (212) were on ARVs. On enquiring from the respondents on changes in alcohol and illicit drugs use after HIV diagnosis, 39.1\% reported having decreased the use, $20 \%$ had increased the use while $40.9 \%$ reported no change.

Using the multidimensional scale of perceived social support, we assessed the respondents for perceived social support from three sources i.e. significant other, family and friends. Four questions were asked for each source of support. Perceived social support was measured on a scale ranging from 4 to 28 . Respondents perceived more social support from significant other (score of 14) and family (score of 13). Most of the respondents did not perceive social support from friends (score of 7). This is as illustrated in table 1 and 2 below.

Table 1:-Perceived Social Support from the Three Sources

\begin{tabular}{|l|l|l|l|}
\hline \multirow{2}{*}{} & \multicolumn{3}{|c|}{ Social Support } \\
\cline { 2 - 4 } & $\begin{array}{l}\text { Significant } \\
\text { other }\end{array}$ & Family & Friends \\
\hline Mean & 14 & 13 & 7 \\
\hline
\end{tabular}

Table 2:-Association between the Various Sources of Perceived Social Support and the Population Characteristics

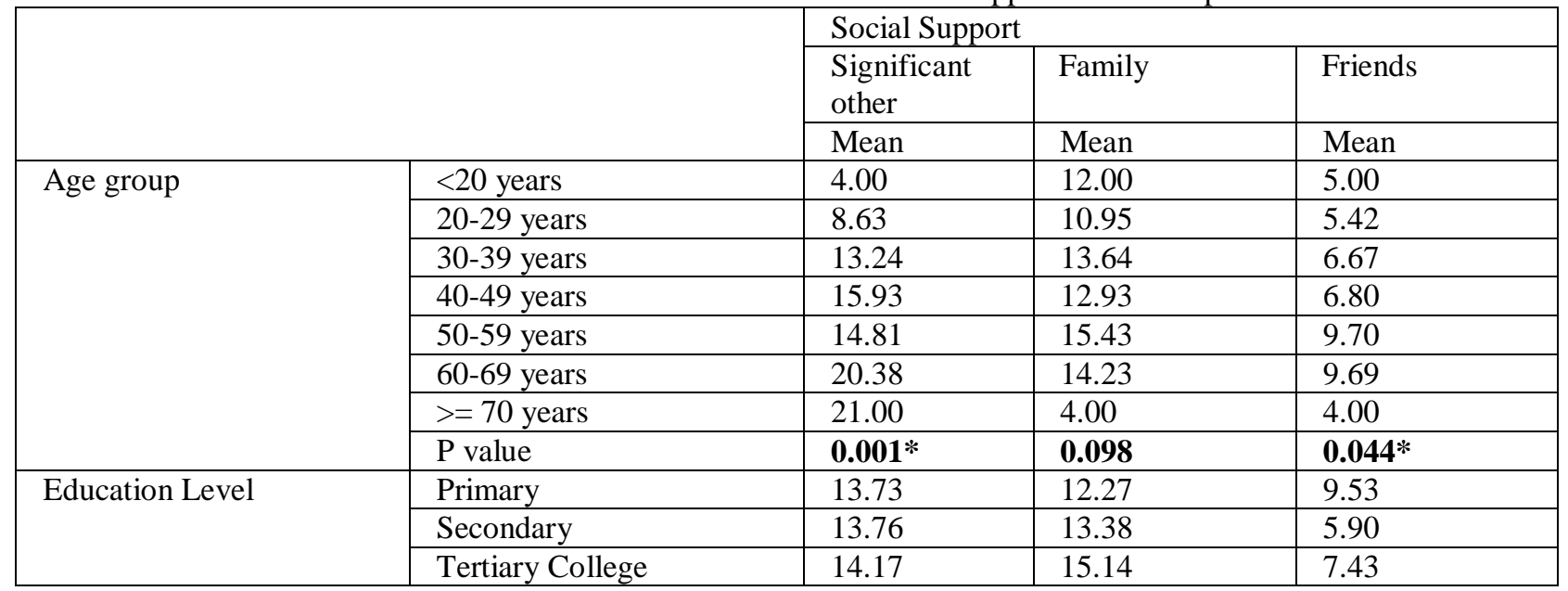




\begin{tabular}{|c|c|c|c|c|}
\hline & University & 4.00 & 8.00 & 4.00 \\
\hline & $\mathrm{P}$ value & 0.561 & 0.154 & 0.001* \\
\hline \multirow[t]{5}{*}{ Marital status } & Single & 5.36 & 13.61 & 5.69 \\
\hline & Married & 22.25 & 12.18 & 7.90 \\
\hline & Separated & 8.16 & 14.50 & 6.60 \\
\hline & Widowed & 6.65 & 14.37 & 7.05 \\
\hline & $P$ value & $<0.0001 *$ & 0.138 & 0.257 \\
\hline \multirow[t]{3}{*}{ Religion } & Christian & 13.97 & 13.54 & 7.00 \\
\hline & Muslim & 12.83 & 12.15 & 7.75 \\
\hline & P value & 0.500 & 0.243 & 0.482 \\
\hline \multirow[t]{5}{*}{ Occupation } & Formally employed & 13.03 & 15.74 & 10.74 \\
\hline & Casual labourer & 14.23 & 11.56 & 6.07 \\
\hline & Self employed & 13.93 & 14.34 & 7.06 \\
\hline & Unemployed & 10.60 & 9.00 & 5.50 \\
\hline & $\mathrm{P}$ value & 0.697 & 0.001* & 0.003* \\
\hline \multirow[t]{3}{*}{ Are you on ARVs } & Yes & 14.14 & 13.45 & 7.22 \\
\hline & No & 10.00 & 12.05 & 6.36 \\
\hline & $P$ value & 0.058 & 0.362 & 0.533 \\
\hline \multirow{3}{*}{$\begin{array}{l}\text { Membership to a support } \\
\text { group }\end{array}$} & Yes & 13.61 & 14.39 & 13.61 \\
\hline & No & 13.76 & 13.22 & 6.60 \\
\hline & $P$ value & 0.951 & 0.488 & $<0.0001 *$ \\
\hline \multirow{4}{*}{$\begin{array}{l}\text { Change in substance use } \\
\text { after HIV diagnosis }\end{array}$} & Increased & 11.40 & 14.45 & 8.30 \\
\hline & Decreased & 14.22 & 13.93 & 6.61 \\
\hline & No change & 14.52 & 12.12 & 7.05 \\
\hline & $\mathrm{P}$ value & 0.172 & 0.082 & 0.303 \\
\hline
\end{tabular}

\section{KEY}

\section{* Significant association:-}

Social support from a significant other was observed to increase with age $(\mathrm{p}=0.001)$ with majority of those perceiving support from a significant other being in the elder age groups. The same was observed of perceived social support from family $(\mathrm{p}=0.044)$.

Social support from friends decreased with a rise in education level $(\mathrm{p}=0.001)$ with those with tertiary and university education perceiving less support from friends. Perceived social support from significant other was significantly high among the married $(\mathrm{p}=<0.0001)$ compared to those who were not married.

There was a significant association between perceived social support from family $(\mathrm{p}=0.001)$ and friends $(\mathrm{p}=0.003)$ and income/earnings with the formally employed and the self- employed perceiving more support than the casual labourers and the unemployed.

Members of HIV/AIDS support groups perceived more social support from friends ( $\mathrm{p}=<0.0001$ ) as compared to those who did not belong to a support group.

\section{Discussion:-}

More males than females were found to be using alcohol and illicit drugs. This can be compared with findings from a study on correlates of substance use among patients which also found that more males than females used substances (Ward C. et al, 2008). Men are more likely to report alcohol use, to drink alcohol more frequently, and to be identified as harmful, hazardous, or likely dependent drinkers than women (Kalichman S. et al, 2007). Despite the fact that the majority of the respondents $90.6 \%$ (212) were on ARVs, only $6.7 \%$ (15) of the respondents were members of a HIV/AIDS support group. This portrays a possible lack of social support in a situation where it is highly necessary and recommended. Non adherence to antiretroviral medication in other studies has been found to be common among clients with perceived low social support (Muya A. et al, 2014). This may have predisposed the respondents to substance use as found out in other studies where inadequate social support was correlated with substance use (Holtz C et al, 2012). 
Respondents perceived more social support from significant other (score of 14) and family (score of 13). Most of the respondents did not perceive social support from friends (score of 7).Most significant is the fact that the few respondents perceiving support from their friends disclosed that the said friends had encouraged them to seek health care at the clinic and were also HIV positive and on follow up at the clinic.

Among the respondents, 39.1\% reported having decreased their use of alcohol and illicit drugs after HIV/AIDS diagnosis while others either increased $(20 \%)$ their use or had no change $(40.9 \%)$. The decrease observed could be attributed to the fact that health workers taking care of HIV/AIDS patients impart knowledge on the risks associated with alcohol and illicit drugs use among this population. This can be supported by the fact that the majority of the respondents attributed their decision to decrease the use of alcohol and illicit drugs to advice from the health workers. A good number of respondents, 40.9\% (96) reported no change in their use of alcohol and illicit drugs. The increase or lack of change was as a result of stress related to the diagnosis as expressed by the respondents. This could be related to the fact that the psychological and physical demands of coping with diagnosis, medications and comorbid illnesses can be overwhelming and may influence behaviour such as alcohol and illicit drugs use and risky sexual behaviour that in turn, affect health outcomes (Gore-Felton, C., \& Koopman, C. (2008). In addition, the use of alcohol and illicit drugs is an impulsive disorder which requires considerable follow up of the individual in order to realise change. Advice alone therefore may not have been a strategy good enough to realise a decrease in alcohol and drugs use among all the respondents.

There was a significant association between social support from a significant other and age $(\mathrm{p}=0.001)$ with the elder age groups perceiving more support from their significant others. This was also the case with perceived social support from the family. This could be attributed to them having built stronger relations over time. The married too perceived more support from their significant others compared to the others maybe because they were in stable relationships with their spouses.

Respondents who were employed (formally or self) perceived more social support from the family than the casual labourers and the unemployed. This was also the case with perceived social support from friends. The formally and the self- employed may have been perceived or really had a good economic status and therefore could have been supported simply because they had a stable means of livelihood. With a means of livelihood, the respondents could have been bread winners and so won support from friends and family.

Respondents with higher level of education i.e. at tertiary and university level perceived less social support from friends. This could be attributed to the fact that people who are learned could have a better understanding on HIV/AIDS compared to the less educated who will keep on enquiring more and in the process make friends. In addition this could paint a grave picture on the level of stigma among the learned. Respondents who were members of a support group had support from friends maybe because they derived friends and thus support from group members. The formally and self-employed had higher levels of perceived social support from friends. A seemingly stable income could have attracted and maybe retained friends to their side.

\section{Limitations of the Study:-}

The study excluded clients below 18 years of age. Those below 18 years but with disorders of alcohol and illicit drugs use would therefore not benefit from the study outcomes. This being a cross sectional study also means that the information collected was inadequate to make causal conclusions.

The researchers however recommend further studies in which interventions such as establishment of support groups and their impact on alcohol and illicit drugs use among this population would be assessed.

\section{Conclusion:-}

Providing social support may decrease the risk of substance use among HIV/AIDS infected clients and hence better health outcomes. Social support should be strengthened as part of the comprehensive care.

Social support is expected to be derived from significant others, family and friends. Perceived lack of social support demotivates PLWHA leading them to engage in risky behaviours such as substance use.

More than advice from healthcare workers is required to curb substance use among PLWHA. Advice should be coupled with referral for further management and follow up since substance use is an impulsive disorder. 


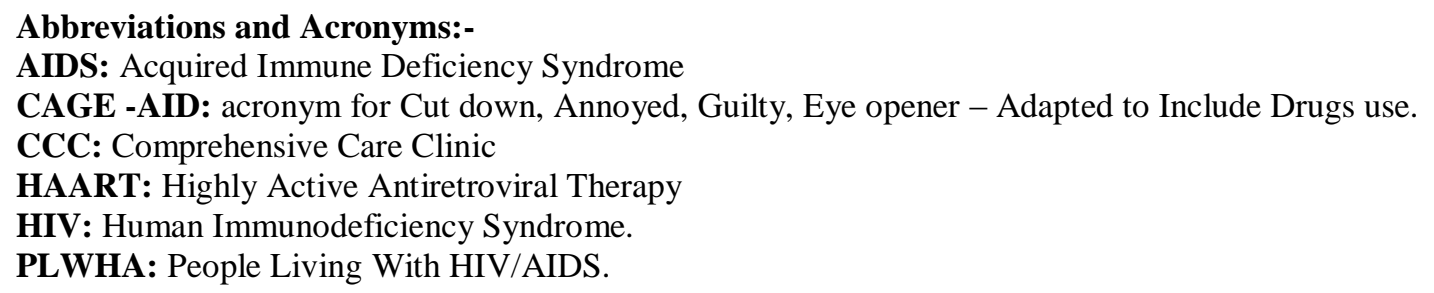

\section{Competing Interests:-}

The authors declare that they have no competing interests.

\section{Authors' Contributions:-}

M.E. conceptualized the study, collected data, wrote the report and drafted the manuscript; W.M., K.A. and K.L. critically revised, provided guidance and supervision throughout the study process and preparation of the manuscript. All authors read and approved the final manuscript.

\section{Acknowledgement:-}

This work was partially funded by the Mental Health linked award of PRIME (Partnership in Research and Innovative Medical Education) -KENYA to the University of Nairobi. We also wish to thank the administration at the Coast General Hospital, Mombasa for the permission to carry out the study in the hospital and the clients at the CCC for participating in the study. All authors read and approved the final manuscript.

\section{References:-}

1. Ewing J.A., 1984. Detecting alcoholism. The CAGE questionnaire. JAMA, 252: 1905-7.

2. Galvan, F. H.,et al, (2008). HIV stigma and social support among African Americans. AIDS Patient Care and STDs, 22(5), 423-36. doi:10.1089/apc.2007.0169

3. Global Initiative on Psychiatry [GIP], 2006. Double stigma, double challenge: Mental health and HIV/AIDS in central and eastern Europe and the newly independent states. An advocacy and information document. Retrieved from http://www.gip-global.org

4. Gore-Felton, C., \& Koopman, C. (2008). Behavioral mediation of the relationship between psychosocial factors and HIV disease progression. Psychosomatic Medicine,70(5),569-74. doi:10.1097/PSY.0b013e318177353e

5. Holtz, C. S., et al, (2012). Oaxacan women with HIV/AIDS: resiliency in the face of poverty, stigma, and social isolation. Women \&Health,52(6),517-35. doi:10.1080/03630242.2012.690839

6. Martinez P., et al, (2008) Alcohol use, depressive symptoms and the receipt of antiretroviral therapy in Southwest Uganda. AIDS Behav.2008; 12:605-612. doi: 10.1007/s10461-007-9312-x. [PMC free $\underline{\text { article] }}[\underline{\text { PubMed] }}[$ Cross Ref]

7. Kalichman, S.C., et al.(2007). Alcohol Use and Sexual Risks for HIV/AIDS in Sub-Saharan Africa: Systematic Review of Empirical Findings. PrevSci, 8: 141. doi:10.1007/s11121-006-0061-2

8. Leserman, J.,et al,(2008). Stressful life events and adherence in HIV. AIDS patient care and STDs, 22(5),pp.403-11.Available at: http://www.pubmedcentral.nih.gov/article/2567910

9. Levi-Minzi, M. A. and Surratt H. L. (2014) HIV stigma among substance abusing people living with HIV/AIDS: implications for HIV treatment.AIDS Patient Care STDS. 28(8): 442-451. doi: 10.1089/apc.2014.0076PMCID: PMC4117265

10. Muya A.N.,et al, 2014. Predictors of Nonadherence to Antiretroviral Therapy among HIV-Infected Adults in Dar es Salaam, Tanzania.J Int Assoc Provid AIDS Care,.14(2):163-71. doi: 10.1177/2325957414539193. Epub 2014 Jun 25.

11. Olagunju A.T., et al, 2015. Late-life depression: Burden, severity and relationship with social support dimensions in a West African community.Arch GerontolGeriatr, 61(2):240-6. doi: 10.1016

12. Sayles, J. N., et al, (2009). The association of stigma with self-reported access to medical care and antiretroviral therapy adherence in persons living with HIV/AIDS. Journal of General Internal Medicine, 24(10), 1101-8. doi: $10.1007 / \mathrm{s} 11606-009-1068-8$

13. Smith N.R.,et al, (2015). The influence of social support on ethnic differences in well-being and depression in adolescents: findings from the prospective Olympic Regeneration in East London (ORiEL) study.

SocialPsychiatry\&PsychiatryEpidemiology,50(11), 1701-1711 
14. Soboka M, et al, (2014) Alcohol use disorders and associated factors among people living with HIV who are attending services in south west Ethiopia. BMC Res Notes. 2014; 7: 828. Published online 2014 Nov 24. doi: 10.1186/1756-0500-7-828.PMCID: PMC4289332

15. Ward, C. L., et al (2008). Prevalence and correlates of substance use among South African primary care clinic patients. Substance Use \& Misuse, 43(10), 1395-410. doi:10.1080/10826080801922744

16. Zhang, Y.-X et al (2014). Coping strategies for HIV-related stigma in Liuzhou, China. AIDS and Behavior, 18 Suppl 2, S212-20. doi:10.1007/s10461-013-0662-2

17. Zimet G.D. et al., 1988.The Multidimensional Scale of Perceived Social Support. Journal of Personality Assessment, 52, 30-41. 